\title{
EFEKTIVITAS ACUYOGA TERHADAP NYERI DISMENORRHEA PADA SISWI PMR SMK 1 DUKUHTURI KABUPATEN TEGAL
}

\author{
Adevia Maulidya Chikmah ${ }^{1}$, Juhrotun Nisa ${ }^{2}$ \\ ${ }^{1}$ depheeya@gmail.com, ${ }^{2}$ nisa.jn20@gmail.com \\ ${ }^{1,2)}$ Program Studi DIII Kebidanan, Politeknik Harapan Bersama Tegal, Indonesia
}

\begin{abstract}
Abstrak
Prevalensi dismenorea di dunia sangat besar yaitu, rata-rata lebih dari $50 \%$ perempuan di setiap dunia mengalaminya. Pelayanan kesehatan remaja sesuai permasalahannya, lebih intensif kepada aspek promotif dan preventif dengan cara "peduli remaja". Upaya penanganan untuk mengurangi dismenore adalah dengan pemberian terapi farmakologi dan nonfarmakologis juga diperlukan untuk mengurangi dismenore, salah satunya dengan menggunakan teknik relaksasi, olah raga dan yoga. Tujuan penelitian ini adalah Efektivitas Acuyoga Terhadap Nyeri Dismenorrhea Pada siswi PMR SMK 1 Dukuhturi Kabupaten Tegal Tahun 2018. Penelitian ini merupakan penelitian kuantitatif dengan rancangan quasy experiment, melakukan pendekatan rancangan peneliti nonequivalent control group design. Populasi pada penelitian ini adalah siswi PMR di SMK 1 Dukuhturi Kabupaten Tegal yang mengalami dysmenorhhea. Analisis yang digunakan adalah Mann-Whitney. Hasil uji analisis menunjukkan asymp. Sig (2 tailed) 0.000, artinya acuyogoga efektif terhadap intensitas nyeri dysmenorhhea.
\end{abstract}

Kata kunci: Acuyoga, Nyeri, Dismenorrhea

\begin{abstract}
The prevalence of dysmenorrhea in the world is very large, that is, on average more than 50\% of women in each world experience it. Adolescent health services according to the problem, more intensive to the promotive and preventive aspects by way of "caring for adolescents". Treatment efforts to reduce dysmenorrhea is by providing pharmacological and nonpharmacological therapy is also needed to reduce dysmenorrhea, one of them by using relaxation techniques, exercise and yoga. The purpose of this study is the Effectiveness of Acuyoga on Pain in Dismenorrhea in PMR students of Dukuhturi 1 Vocational School in Tegal Regency in 2018. This research is a quantitative study with a quasy experiment design, approaching the design of non-equivalent control group design researchers. The population in this study was PMR students at Dukuhturi Vocational High School 1 Tegal Regency who had dysmenorhhea. The analysis used was MannWhitney. The test results of the analysis show asymp. Sig (2 tailed) 0,000, meaning that acuyogoga is effective against the intensity of dysmenorhhea pain.
\end{abstract}

Keywords: Acuyoga, Pain, Dismenorrhea

\section{Pendahuluan}

Masa remaja adalah masa peralihan dari masa kanak-kanak ke masa dewasa yaitu antara usia sebelas tahun sampai empat belas tahun hingga dua puluh tahun ${ }^{[1]}$. Pada saat ini perempuan akan mengalami ovulasi dan menstruasi. Permasalahan nyeri haid adalah permasalahan yang sering dikeluhkan saat perempuan datang ke dokter atau tenaga kesehatan yang berkaitan dengan haid. Kondisi ini dapat bertambah parah bila disertai dengan kondisi psikis yang tidak stabil. Nyeri haid dapat menyerang perempuan yang mengalami haid pada usia berapapun ${ }^{[2]}$.

Dismenore adalah nyeri selama menstruasi yang disebabkan oleh kejang otot uterus ${ }^{[3]}$.

Prevalensi dismenorea di dunia sangat besar yaitu, rata-rata lebih dari $50 \%$ perempuan di setiap dunia 
mengalaminya ${ }^{[4]}$. Presentase dismenore di Amerika Serikat diperkirakan hampir 90\% wanita mengalami dismenore dan $10-15 \%$ diantaranya mengalami dismenore berat ${ }^{[5]}$. Prevalensi di Malaysia prevalensi dismenore pada remaja sebanyak $62,3 \% \%^{[6]}$. Prevalensi dismenore di Swedia 72\%, dan prevalensi dismenore di Indonesia sebesar $64,25 \%$ yang terdiri dari $54,88 \%$ dismenore primer dan $9,36 \%$ dismenore sekunder ${ }^{[7]}$.

Upaya pemerintah dalam menghadapi kesehatan remaja diatur dalam UU nomor 36 tahun 2009 tentang kesehatan mencantumkan tentang kesehatan reproduksi pada bagian keenam pasal 71 sampai dengan pasal 77. Pada pasal 71 ayat 3 mengamanatkan bahwa kesehatan reproduksi dilaksanakan melalui kegiatan promotif, preventif, kuratif, dan rehabilitatif. Beberapa tahun terakhir mulai dilaksanakan beberapa model pelayanan kesehatan remaja yang memenuhi kebutuhan, hak dan "selera" remaja di beberapa Propinsi, dan diperkenalkan dengan sebutan Pelayanan Kesehatan Peduli Remaja atau disingkat PKPR. Sebutan ini merupakan terjemahan dari istilah adolescent friendly health services (AFHS), yang sebelumnya dikenal dengan youth friendly health services (YFHS). Pelayanan kesehatan remaja sesuai permasalahannya, lebih intensif kepada aspek promotif dan preventif dengan cara "peduli remaja". Memberi layanan pada remaja dengan model PKPR ini merupakan salah satu strategi yang penting dalam mengupayakan kesehatan yang optimal bagi remaja. Pelayanan kesehatan peduli remaja diselenggarakan di puskesmas, rumah sakit, dan tempat-tempat dimana remaja berkumpul ${ }^{[8]}$.

Upaya penanganan untuk mengurangi dismenore adalah dengan pemberian terapi farmakologi seperti obat analgetik, terapi hormonal terapi dengan obat non steroid anti prostaglandin dan dilatasi kanalis servikanalis ${ }^{[9]}$. Pengaruh nonfarmakologis juga diperlukan untuk mengurangi dismenore, salah satunya dengan menggunakan teknik relaksasi, olah raga dan yoga ${ }^{[10]}$.

Acuyoga adalah kombinasi dari pengetahuan akupunktur atau akupresur dan yoga. Di dalam acuyoga, meddis ilmiah dimodifikasi menggunakan istilah asana, pranayam,dan meditasi. Dalam acuyoga, teknik relaksasi disarankan agar dapat mengatur aliran energi vital dari organ yang bermasalah. Energi vital disebut prana (dalam yoga) atau qi (dalam akupunktur) dan ki (dalam pengobatan jepang). Dalam sistem ini, pengobatan dilakukan terhadap tubuh yang terdiri atas fisik, mental (emosional), dan psikis (spiritual/rohani), bukan hanya fokus pada penyakit. Seperti halnya akupunktur/akupresur, acuyoga juga menggunakan titik-titik meridian organ dalam tubuh. Energi ini berjalan dan mengalir melalui meridian-meridian dalam tubuh secara melintang dan mendatar. Ketika energi hidup (qi) tersumbat maka peredaran meridian yang dapat menyebabkan gangguan fisik dan emosi akan terhambat ${ }^{[1]}$.

Yoga adalah salah satu teknik relaksasi yang dianjurkan untuk menghilangkan nyeri haid. Pelatihan yang terarah dan berkesinambungan dipercaya mampu menyembuhkan nyeri haid dan menyehatkan badan secara keseluruhan $^{2}$. Manfaat berlatih yoga diantaranya, meningkatkan sirkulasi darah keseluruh tubuh, meningkatkan kapasitas paru saat bernafas, mengurangi ketegangan tubuh, fikiran dan mental, serta mengurangi rasa nyeri. Selain itu yoga juga dipercaya dapat mengurangi cairan yang menumpuk di bagian pinggang yang menyebabkan nyeri saat haid $^{[11]}$.

Dalam kondisi rileks, tubuh menghentikan produksi hormon adrenalin dan semua hormon yang diperlukan saat kita stres. Oleh karena 
hormon seks estrogen dan progesteron serta hormon stres adrenalin, diproduksi dari blok bangunan bangunan kimiawi yang sama. Ketika kita mengurangi stres, berarti kita juga telah mengurangi produksi kedua hormon seks tersebut. Dengan demikian kita dapat melihat pentingnya relaksasi untuk memberikan kesempatan bagi tubuh memproduksi hormon yang penting untuk mendapatkan haid tanpa rasa nyeri ${ }^{[12]}$.

Tujuan penelitian ini adalah Mengidentifikasi Efektivitas Acuyoga Terhadap Nyeri Dismenorrhea Pada Siswi PMR SMK 1 Dukhturi Kabupaten Tegal Tahun 2018.

\section{Metode Penelitian}

Penelitian ini merupakan penelitian kuantitatif dengan rancangan quasy experiment, melakukan pendekatan rancangan peneliti nonequivalent control group design. Terdapat 2 kelompok yaitu kelompok control yaitu kelompok yang tidak diberikan acuyoga dan kelompok intervensi yaitu kelompok yang diberikan acuyoga. Masing-masing kelompok dinilai tingkat nyeri haidnya. Tingkatan nyeri dinilai pada awal penelitian dan diamati kembali setelah responden mengalami menstruasi dibulan berikutnya. Populasi yang diteliti adalah siswi PMR SMK 1 Dukuhturi yang mengalami dismenorhhea. Teknik pembagian kelompok dilakukan secara acak. Analisis data yang digunakan ManWhitney

\section{Hasil dan Pembahasan}

a. Karakteristik responden

\begin{tabular}{|c|c|c|c|c|c|c|}
\hline \multirow{3}{*}{ Karakteristik } & \multicolumn{4}{|c|}{ Kelompok } & \multicolumn{2}{|c|}{ Total } \\
\hline & \multicolumn{2}{|c|}{ Intervensi } & \multicolumn{2}{|c|}{ Kontrol } & \multirow[b]{2}{*}{$\mathrm{F}$} & \multirow[b]{2}{*}{$\%$} \\
\hline & Frekuensi & $\%$ & Frekuensi & $\%$ & & \\
\hline \multicolumn{7}{|l|}{ Menarche } \\
\hline$<15$ th & 11 & 42,3 & 13 & 50 & 24 & 92,3 \\
\hline$>15$ th & 2 & 7,7 & 0 & 0 & 2 & 7,7 \\
\hline \multicolumn{7}{|l|}{ Siklus } \\
\hline Teratur & 7 & 26,9 & 8 & 30,8 & 15 & 57,7 \\
\hline Tidak teratur & 6 & 23,1 & 5 & 19,2 & 11 & 42.3 \\
\hline \multicolumn{7}{|l|}{ Jenis } \\
\hline Primer & 4 & 15,3 & 9 & 34,7 & 13 & 50 \\
\hline Sekunder & 9 & 34,7 & 4 & 15,3 & 13 & 50 \\
\hline \multicolumn{7}{|l|}{ Lama } \\
\hline 1 Hari & 5 & 19,2 & 5 & 19,2 & 10 & 38,4 \\
\hline$>1$ Hari & 8 & 30,8 & 8 & 30,8 & 16 & 61,6 \\
\hline
\end{tabular}

Sumber: data primer

Tabel diatas menunjukkan bahwa usia pertama kali haid yang paling banyak yaitu usia < 15 tahun (92,3\%). 15 Siswi $(57,7 \%)$ mempunyai siklus haid yang teratur. Jenis dysmenorrhea yang dialami baik dysmenorrhea primer maupun sekunder sama. Sedangkan lamanya Dysmenorrhea 16 siswi $(61,6 \%)$ mempunyai lama Dysmenorrhea $>1$ hari.

Menarche dapat menimbulkan berbagai masalah salah satunya yaitu keluhan nyeri saat menstruasi atau yang biasa disebut dismenore. Dismenore yaitu suatu kondisi yang dirasakan saat sebelum atau pada saat menstruasi yang ditandai dengan rasa nyeri atau kram pada 
perut bagian bawah yang timbul karena kontraksi pada distrimik miometrium yang berupa nyeri dan bukan karena suatu penyakit tertentu $^{[13]}$.

Sejalan dengan penelitian Wulandari \& Ungsianik (2013) bahwa Umur menarche yang terlalu dini $(<\quad 12$ tahun $)$ mengakibatkan ketidaksiapan maupun masalah bagi remaja yaitu merasakan nyeri saat menstruasi dikarenakan organorgan reproduksi yang belum berkembang secara maksimal dan adanya penyempitan pada leher rahim atau pematangan organ reproduksi ${ }^{[14]}$.

Dismenore muncul berupa serangan ringan, kram pada bagian tengah, bersifat spasmodis yang dapat menyebar ke punggung atau paha bagian dalam. Umumnya ketidaknyamanan di mulai 1-2 hari sebelu menstruasi, namun nyeri yang paling berat selama 24 jam pertama menstruasi dan mereda pada hari kedua ${ }^{[15]}$.

b. Intensitas Nyeri Dysmenorrhea

Tabel 2. Intensitas Nyeri Dysmenorrhea

\begin{tabular}{|c|c|c|c|c|c|c|c|c|}
\hline \multirow{4}{*}{ Kelompok } & \multicolumn{8}{|c|}{ Intensitas Nyeri } \\
\hline & \multicolumn{4}{|c|}{ Sebelum } & \multicolumn{4}{|c|}{ Sesudah } \\
\hline & \multicolumn{2}{|c|}{ Sedang } & \multicolumn{2}{|c|}{ Hebat } & \multicolumn{2}{|c|}{ Sedang } & \multicolumn{2}{|c|}{ Hebat } \\
\hline & $\mathrm{F}$ & $\%$ & $\mathrm{~F}$ & $\%$ & $\mathrm{~F}$ & $\%$ & $\mathrm{~F}$ & $\%$ \\
\hline Intervensi & 6 & 23,1 & 7 & 26,9 & 12 & 46,1 & 1 & 3,9 \\
\hline Kontrol & 8 & 30,7 & 5 & 19,3 & 9 & 34,6 & 4 & 15,4 \\
\hline Total & 14 & 53,8 & 12 & 46,2 & 21 & 80,7 & 5 & 19,3 \\
\hline
\end{tabular}

Berdasarkan tabel di atas bahwa intensitas nyeri pada kelompok intervensi sebelum dilakukan acuyoga mempunyai intensitas nyeri hebat sebanyak 7 siswi (26,9\%), dan setelah dilakukan acuyoga jumlah responden dengan intensitas nyeri hebat menjadi 1 siswi (3,9\%). Sedangkan kelompok kontrol 8 siswi $(30,7 \%)$ mempunyai intensitas nyeri sedang, dan 9 siswi $(34,6 \%)$ mempunyai intensitas nyeri sedang setelah responden haid bulan berikutnya.

c. Rata-rata Intensitas Nyeri

Tabel 3. Rata-rata Intensitas Nyeri

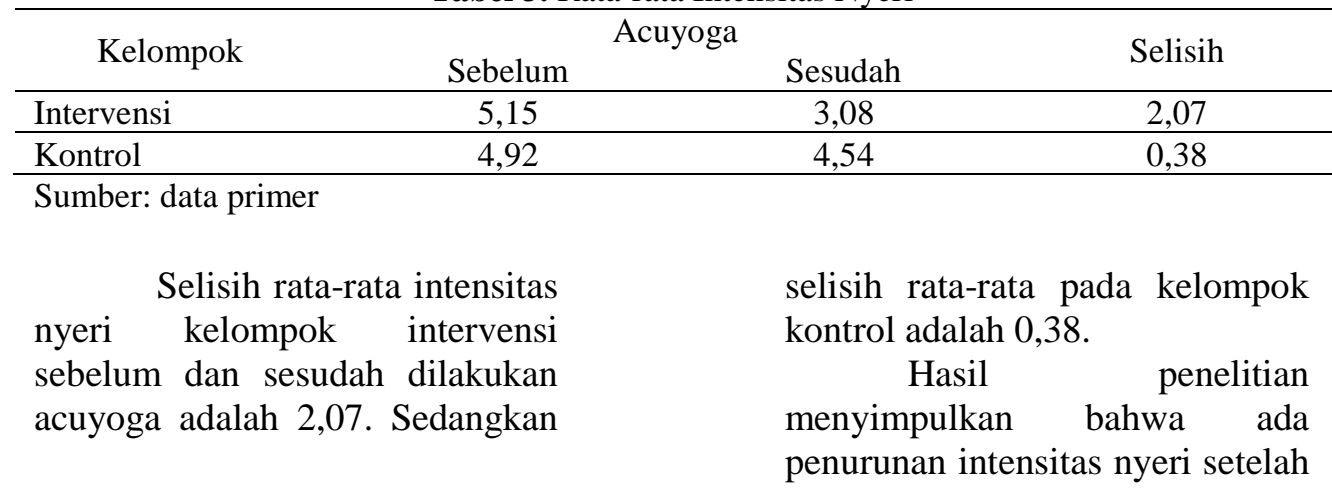


dilakukan acuyoga pada siswi SMK 1 Dukuhturi. Nyeri dysmenorhhea yang hebat menjadi sedang, beberapa responden mengatakan badan lebih enak setelah dilakkan acuyoga dan nyeri haid pun tidak begitu terasa.

d. Efektivitas Acuyoga Terhadap Intensitas Nyeri dysmenorrhea

Tabel 4. Efektivitas Acuyoga Terhadap Intensitas Nyeri dysmenorrhea

\begin{tabular}{lcccc}
\hline \multirow{2}{*}{ Kelompok } & \multicolumn{2}{c}{ Acuyoga } & \multirow{2}{*}{ Selisih } & \multirow{2}{*}{ Efektivitas } \\
& Sebelum & Sesudah & & \\
\hline Intervensi & 5,15 & 3,08 & 2,07 & Asymp. Sig \\
Kontrol & 4,92 & 4,54 & 0,38 & $\begin{array}{c}\text { (2 tailed }) \\
0.000\end{array}$ \\
\hline
\end{tabular}

Sumber: data primer

$\begin{array}{ccc}\text { Hasil uji } & \text { analisis } \\ \text { menggunakan man } & \text { whitney }\end{array}$ menunjukkan asymp. Sig (2 tailed) 0.000 , artinya acuyogoga efektif terhadap intensitas nyeri dysmenorhhea.

Yoga adalah suatu cara tehnik relaksasi, tehnik relaksasi memberikan efek distraksi yang dapat mengurangkan nyeri kram abdomen akibat dismenorea ${ }^{[16]}$. Efek relaksasi juga memberikan individu kontrol diri ketika terjadi rasa tidak nyaman atau nyeri, stres fisik, emosi serta menstimulus pelepasan endorfin $^{[17]}$. Pelepasan endorfin dapat meningkatkan respons saraf parasimpatis yang mengakibatkan vasodilatasi pembuluh darah seluruh tubuh dan uterus serta meningkatkan aliran darah uterus sehingga mengurangi intensitas nyeri dismenorea ${ }^{[18]}$.

Secara fisiologis teknik akupressur dapat menurunkan nyeri, hal ini sesuai dengan teori Gate Control yang menyatakan rangsangan rangsangan nyeri dapat diatur atau bahkan dihalangi oleh pintu mekanisme sepanjang sistem pusat neurons. Gat e dapat di t emukan di dal am sel - sel gelatinosa dengan tanduk tulang belakang pada ujung syaraf tulang belakang, talamus dan sistem limbic ${ }^{[19]}$. Teori ini menyatakan bahwa rangsangan akan dirintangi ketika sebuah pintu tertutup. Penutupan pintu adalah dasar untuk terapi pertolongan rasa sakit $^{[20]}$. Acuyoga adalah kombinasi dari pengetahuan akupunktur atau akupresur dan yoga. Di dalam acuyoga, meddis ilmiah dimodifikasi menggunakan istilah asana, pranayam,dan meditasi. Dalam acuyoga, teknik relaksasi disarankan agar dapat mengatur aliran energi vital dari organ yang bermasalah. Energi vital disebut prana (dalam yoga) atau qi (dalam akupunktur) dan ki (dalam pengobatan jepang). Dalam sistem ini, pengobatan dilakukan terhadap tubuh yang terdiri atas fisik, mental (emosional), dan psikis (spiritual/rohani), bukan hanya fokus pada penyakit ${ }^{[1]}$. 


\section{Kesimpulan}

Responden yang mengalami menarche di Usia $<15$ tahun $(92,3 \%)$, 15 Siswi $(57,7 \%)$ mempunyai siklus haid yang teratur, jenis dysmenorrhea yang dialami baik dysmenorrhea primer maupun sekunder sama banyaknya baik oleh kelompok intervensi maupun kontrol. Sedangkan lamanya Dysmenorrhea 16 siswi $(61,6 \%)$ mempunyai lama Dysmenorrhea $>1$ hari.

Intensitas nyeri pada kelompok intervensi sebelum dilakukan acuyoga mempunyai intensitas nyeri hebat sebanyak 7 siswi (26,9\%), dan setelah dilakukan acuyoga jumlah responden dengan intensitas nyeri hebat menjadi 1 siswi (3,9\%). Sedangkan kelompok kontrol 8 siswi $(30,7 \%)$ mempunyai intensitas nyeri sedang, dan 9 siswi $(34,6 \%)$ mempunyai intensitas nyeri sedang setelah responden haid bulan berikutnya.

Selisih rata-rata intensitas nyeri kelompok intervensi sebelum dan sesudah dilakukan acuyoga adalah 2,07. Sedangkan selisih rata-rata pada kelompok kontrol adalah 0,38.

Hasil uji analisis menggunakan man whitney menunjukkan asymp. Sig (2 tailed) 0.000, artinya acuyogoga efektif terhadap intensitas nyeri dysmenorhhea.

\section{Daftar Pustaka}

[1] Wong, Ferry M. Acuyoga. Depok: Penebar Plus. 2011.

[2] Anurogo D. \& Wulandari A. Cara Jitu Mengatasi Nyeri Haid. Yogyakarta: penerbit ANDI. 2011.

[3] Wilson, L. M. \& Price, S.A. Patofisiologi: Konsep klinis proses-proses penyakit. Jakarta: penerbit Buku Kedokteran EGC. 2006.
[4] Ningsih, R. Efektifitas paket pereda terhadap intensitas nyeri pada remaja dengan dismenore di SMAN Kecamatan Curup. Diperoleh tanggal 11 januari 2015 dari http;//www.lontar.ui.ac.id

[5] Wong, dkk. Buku ajar keperawatan pediatrik. (Vol 1). Jakarta: EGC. 2008.

[6] Liliwati, Vera \& Khairani, 2007

[7] Husain,O. Hubungan pengetahuan tentang dismenore dengan upaya penanganan pada siswi kelas $X$ di SMKN 1 Batudaa. Di peroleh pada tanggal 3 Desember 2014 di http://kim.ung.ac.id/index.php/KI MFIKK/article/ download/2841/2817.

[8] Anonim. Problematika Remaja Akibat Kurangnya Informasi Kesehatan Reproduksi. http://www.esaunggul.ac.id/

Diperoleh Tanggal 23 Maret 2013.

[9] Mitayani. Asuhan Keperawatan Maternitas. Jakarta: Salimba Medika. 2009.

[10] Asmarani, D. Yoga Untuk Semua. Jakarta: Gramedia. 2011.

[11] Suratini. Panduan Praktikum Keperawatan keluarga. STIKES Aisyah Yogyakarta. 2013.

[12] Trimayasari, D., \& Kuswandi, K. Hubungan Usia Menarche dan Status Gizi Siswi SMP Kelas 2 Dengan Kejadian Dismenore. Jurnal Obstretika Scientia. 2(2), 192-211. https://doi.org/ISSN 2337-6120

[13] Wulandari, S., \& Ungsianik, T. Status Gizi, Aktivitas Fisik, dan Usia Menarche Remaja Putri. Jurnal Keperawatan Indonesia. 16(1), 55-59. Retrieved from journal.ui.ac.id

[14] Wronka I, Teul I,Marchewka I. The influence of age at menarche 
on the prevalence of disorders of the menstrual cycle among Healthy University Students. Annales Academiae Medicae Stetinensis. 59(2), 94-8.

[15] Icedestariblog. Tanda dan Gejala Dismenorea.

https://icedestariblog.wordpress.c om/2016/05/28/tanda-dan-gejaladesminore/

[16] Sindhu, Pujiastuti. Panduan lengkap yoga untuk hidup sehat dan seimbang. Bandung: Qanita. 2014.

[17] Simkin, P., Whalley, J., \& Keppler, A. Panduan lengkap kehamilan, melahirkan, dan bayi. Jakarta: ARCAN. 2008.

[18] Ernawati, Hartiti, T., \& Idris, H. Terapi relaksasi terhadap nyeri dismenore pada mahasiswi universitas muhammadiyah semarang. Prosiding Seminar Nasional UNIMUS. 106-113. Diperoleh pada tanggal 23 Januari 2015 http://jurnal.unimus.ac.id/index.ph $\mathrm{p} / \mathrm{psn} 1$ 2012010/article/view/54/28

[19] Tjahjati Juni, Ismail. Akupuntur Analgetik di Bidang Anastesi. Medica (Jurnal Kedokteran Dan Farmasi). 2001. I (XXVII).

[20] Pottern, P , Ann Griff i n Pery. Fundamental of Nursing : Consep Process And Predicte, 4th ed. Missoury : Mosby year Book Inc st Louis. 